\title{
Conventional Synthesis of Amphiphilic Block Copolymer Utilized for Polymeric Micelle by Mechanochemical Solid-State Polymerization
}

\author{
Shin-ichi Kondo, ${ }^{*}$ Hisato Mori, Yasushi SASAI, and Masayuki KuzuYa \\ Laboratory of Pharmaceutical Physical Chemistry, Gifu Pharmaceutical University; 5-6-1 Mitahora-Higashi, Gifu \\ 502-8585, Japan. Received September 13, 2006; accepted December 25, 2006; published online December 25, 2006
}

\begin{abstract}
The first example is presented here of an amiphiphilic block copolymer synthesized by mechanochemical solid-state polymerization and used to form polymeric micelles. A model amphiphilic block copolymer was synthesized first, possessing galactose as a hydrophilic side chain and theophylline as a hydrophobic side chain, by mechanochemical solid-state polymerization. The resulting copolymer had a narrow molecular weight distribution. Polymeric micelle formation was subsequently carried out with the copolymer by a dialysis method. To gain insight into the physicochemical properties of the polymeric micelle, dynamic light scattering (DLS) measurements were performed. A narrow distribution of diameters was observed in the polymeric micelle solution, and these micelles were disrupted by the addition of sodium dodecyl sulfate (SDS). It was also confirmed by DLS measurements that the polymeric micelles were spherical. These results suggested that the block copolymer synthesized by mechanochemical solid-state polymerization was as suitable for the preparation of polymeric micelles as materials obtained by living polymerization.
\end{abstract}

Key words mechanochemical polymerization; amphiphilic block copolymer; polymeric micelle; solid-state; light scattering measurement

It has been known that amphiphilic block copolymers consisting of a hydrophilic and a hydrophobic block can form core-shell micelles in a selective solvent for one of the blocks due to the association of the insoluble block. The micelles formed are referred to as "polymeric micelles." Such micelles have attracted much attention in drug delivery systems because of their ability to solubilize hydrophobic molecules; nanoscale size; good thermodynamic solution stability; extended release of various drugs; and prevention of rapid clearance by the reticuloendothelial system. ${ }^{1-10)}$ One needs to use model polymers with well-controlled molecular weight, narrow molecular weight distribution, and low compositional heterogeneity for systematic studies of micellar properties. Living polymerization is eminently suitable to prepare block copolymers with these properties. ${ }^{11-15)}$ However, there are several problems in synthesizing block copolymers by living polymerization. Living polymerization would be unsuitable for a monomer possessing a reactive group such as a drug as a side chain due to the occurrence of side reactions. Such a polymerization is often carried out at low temperature $\left(e . g .,-78^{\circ} \mathrm{C}\right)$ to avoid side reactions, and strict reaction conditions are required to obtain polymers with a well-defined structure.

We have reported the syntheses of and drug release from polymeric prodrugs prepared by mechanochemical solidstate polymerization ${ }^{16-27)}$ carried out by vibratory ballmilling of solid monomer in a metallic vessel under anaerobic conditions. It was found from a series of such studies that this method was applicable to a wide variety of vinyl monomers of an important class of bioactive compounds with different physicochemical properties, and also provided a simple, novel methodology for the synthesis of functionalized polymers through a totally dry process. ${ }^{21)}$ Several features of the present reaction were: the resulting polymeric prodrugs were of narrow molecular weight distribution represented by $M_{\mathrm{w}} / M_{\mathrm{n}},\left(M_{\mathrm{w}}\right.$, weight average molecular weight; $M_{\mathrm{n}}$, number average molecular weight); block copolymers could readily be obtained by this method with a polymer and a monomer in a non-metallic vesse ${ }^{23)}$; and a vinyl monomer possessing a drug as a side chain could be polymerized by mechanochemical solid-state polymerization without detectable side-reactions. It was hoped that if amphiphilic block copolymers synthesized by this type of polymerization could form polymeric micelles, this method would be more convenient than living polymerization, which is frequently used to synthesize block copolymers for polymeric micelles. To our knowledge, polymeric micelle formation from block copolymers produced by mechanochemical solid-state polymerization has not yet been reported.

In this study, we synthesized a model amphiphilic block copolymer, which possessed galactose as a hydrophilic side chain and theophylline as a hydrophobic side chain, by mechanochemical solid-state polymerization, and formed micelles from the copolymer. The physicochemical properties (particle diameter distribution and morphology) of the polymeric micelles obtained were estimated by dynamic light scattering.

\section{Experimental}

Ultraviolet spectral measurements were performed with a Shimadzu Recording Spectrophotometer UV-3100 using 1-cm quartz cells. ${ }^{1} \mathrm{H}-\mathrm{NMR}$ spectra were run on a JEOL JNM-EX400 FT-NMR spectrometer using tetramethylsilane as an internal or external standard. Measurements of $\mathrm{pH}$ were carried out on a TOA pH meter HM-16S at room temperature. Melting points (uncorrected) were measured on a capillary melting-point apparatus. IR spectra were obtained on a Perkin Elmer Spectrum One FT-IR spectrometer. Mass spectra were obtained on a JEOL JMS-SX102A mass spectrometer.

Materials 2-Methacryloyloxyethyl isocyanate and 6-O-methacryloyl-Dgalactopyranose (MGP) were synthesized according to their respective literature procedures. ${ }^{23,25}$ Sodium dodecyl sulfate (SDS) was reagent grade and used as received from Kishida Chemical Co., Ltd.

7-(2-(Methacryloyloxy)ethylcarbamoyl)theophylline (Te) 2-Methacryloyloxyethyl isocyanate $(0.52 \mathrm{~g}, 3.4 \mathrm{mmol})$ was added to a solution of theophylline $(0.50 \mathrm{~g}, 2.8 \mathrm{mmol})$ and triethylamine $(0.28 \mathrm{~g}, 2.8 \mathrm{mmol})$ in dry acetonitrile $(100 \mathrm{ml})$. The reaction mixture was stirred at room temperature overnight, then filtered and evaporated in vacuo. The residue was recrystallized from ethanol to yield $0.47 \mathrm{~g}(50 \%)$ of $\mathrm{Te}, \mathrm{mp} 151-152^{\circ} \mathrm{C}$. IR $(\mathrm{KBr})$ $\mathrm{cm}^{-1}: 3340$ (-CONH-), 1735, 1710, 1705 (carbonyl group), 1650 (vinyl group). ${ }^{1} \mathrm{H}-\mathrm{NMR}$ (DMSO- $\left.d_{6}\right) \delta: 1.60\left(3 \mathrm{H}, \mathrm{s},-\mathrm{CH}_{3}\right.$ of methacryloyl group), 

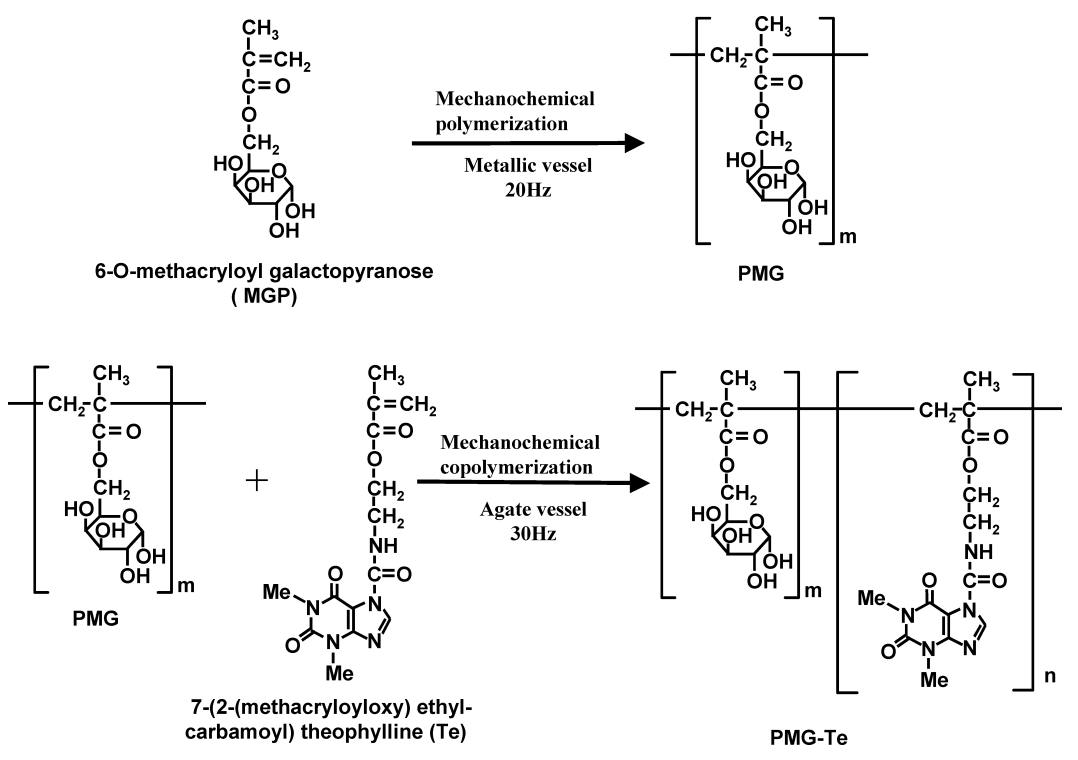

Chart 1

$3.30-3.50\left(8 \mathrm{H}, \mathrm{m},-\mathrm{CH}_{3}\right.$ of theophylline and $\left.-\mathrm{CH}_{2}-\right), 4.00\left(2 \mathrm{H}, \mathrm{t},-\mathrm{CH}_{2}-\right)$, $5.60\left(1 \mathrm{H}, \mathrm{s},=\mathrm{CH}_{2}\right), 5.90\left(1 \mathrm{H}, \mathrm{s},=\mathrm{CH}_{2}\right), 8.52(1 \mathrm{H}, \mathrm{s}, \mathrm{H}-6$ of theophylline $)$, $10.00(1 \mathrm{H}$, br, $-\mathrm{NH}-)$ EI-MS m/z: $335\left(\mathrm{M}^{+}\right)$. Anal. Calcd for $\mathrm{C}_{14} \mathrm{H}_{17} \mathrm{~N}_{5} \mathrm{O}_{5}: \mathrm{C}$, 50.15; H, 5.11; N, 20.89. Found: C, 50.09; H, 5.03; N, 20.90.

Synthesis of Block Copolymer by Mechanochemical Polymerization A measured quantity $(100 \mathrm{mg})$ of MG was mechanically fractured under anaerobic conditions (e.g. in nitrogen) by a mixer mill Type MM 200 (Retsch Co., Ltd.) equipped with a stainless steel ball $(6.0 \mathrm{~mm} \phi, 890 \mathrm{mg})$ in a stainless steel twin-shell blender ( $14 \mathrm{~mm} \phi, 65 \mathrm{~mm}$ long) at room temperature for $1 \mathrm{~h}$ at $20 \mathrm{~Hz}$. Residual oxygen in this system was removed with a Model 1000 Oxygen Trap (Chromatography Research Supplies) coupled with an Indicating Oxygen Trap (Chromatography Research Supplies). The oxygen concentration was monitored with an oxygen analyzer (Toray Engineering Co., Ltd., LC 750/PC-120) and kept below 10 ppm. 7-(2-(Methacryloyloxy)ethylcarbamoyl)theophylline ( $\mathrm{Te}, 23.0 \mathrm{mg}$ ) was added to the fractured MG powder. The mixture was mechanically fractured under anaerobic conditions by a mixer mill Type MM 200 equipped with an agate ball $(6.0 \mathrm{~mm} \phi, 890 \mathrm{mg})$ in an agate twin-shell blender $(14 \mathrm{~mm} \phi, 65 \mathrm{~mm}$ long) at room temperature for $1 \mathrm{~h}$ at $30 \mathrm{~Hz}$. The vinyl proton peaks of Te were undetectable in the ${ }^{1} \mathrm{H}$-NMR spectrum of the resulting powder.

Preparation of Polymeric Micelles The block copolymer $(50 \mathrm{mg}$ ) was first dissolved in dimethyl sulfoxide (DMSO) $(2 \mathrm{ml})$. This solution was transferred through a $0.45 \mu \mathrm{m}$ filter (GL Chromatodisc 13N, GL Sciences Inc.) into a pre-swollen semi-permeable membrane (Spectra/Por, Spectrum Laboratories, Inc.; molecular weight cutoff $3500 \mathrm{~g} / \mathrm{mol}$ ), and dialyzed against $500 \mathrm{ml}$ of water for $24 \mathrm{~h}$ to form the micelles. The dialysate water was exchanged at $3 \mathrm{~h}$.

Molecular Weight Measurement The molecular weight of the block copolymer was measured with a gel permeation chromatograph (GPC; Shimadzu LC-6A) equipped with a refractive index detector (Shimadzu, RID6A), gel column (Shodex, GF-7MHQ and GS-2G7B), and a data analyzer (Shimadzu, Chromatopac C-R4A), under the following conditions: elution solvent, DMF containing $10 \mathrm{mmol}$ of $\mathrm{LiBr}$; flow rate, $0.7 \mathrm{ml} / \mathrm{min}$; column temperature, $40^{\circ} \mathrm{C}$. Calibration was carried out with a standard specimen of poly(ethylene oxide).

Light Scattering Dynamic light scattering measurements were performed using a dynamic light scattering spectrophotometer (DLS-5500G, Photal, Otsuka Electronics) with a $\mathrm{He} / \mathrm{Ne}$ laser. A scattering angle of $90^{\circ}$ was used in this study. The hydrodynamic diameters of micelles and the polydispersity factor of micelles, represented as $\mu_{2} / \Gamma^{2}$, were calculated using the Stokes-Einstein equation and the cumulant method.

\section{Results and Discussion}

Synthesis of Amphiphilic Block Copolymer The amphiphilic block copolymer, PMG-Te, was successfully synthesized by mechanochemical block copolymerization according to Chart 1 . The homopolymer of 6-O-methacryloyl-

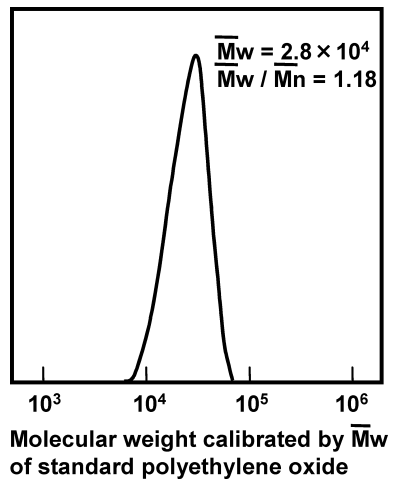

Fig. 1. Gel Permeation Chromatogram of the Amphiphilic Block Copolymer, PMG-Te

D-galactopyranose (MGP), PMG, was obtained by mechanochemical solid-state polymerization of MGP using a metallic vessel at $20 \mathrm{~Hz}$ for $1 \mathrm{~h}$ under anaerobic conditions. The weight average molecular weight $\left(M_{\mathrm{w}}\right)$ of $\mathrm{PMG}$ was $45000 \mathrm{~g} / \mathrm{mol}$ and its polydispersity $\left(\mathrm{PDI}=M_{\mathrm{w}} / M_{\mathrm{n}}\right)$ was 1.28 . When a mixture of PMG and 7-(2-methacryloyloxy)ethylcarbamoyl)theophylline (Te), which contained $15 \mathrm{~mol} \%$ of $\mathrm{Te}$ versus MGP units, was fractured using an agate vessel at $30 \mathrm{~Hz}$ for $1 \mathrm{~h}$ under anaerobic conditions, the peaks of vinyl protons of Te disappeared to below the limit of detection in the ${ }^{1} \mathrm{H}-\mathrm{NMR}$ spectrum of the resulting fractured powder. It was confirmed that Te did not undergo mechanochemical solid-state polymerization in the agate vessel and that PMG produced mechanoradicals under the same mechanical conditions. These results suggested that the mechanoradicals produced by the fracture of PMG reacted with Te to form the amphiphilic block copolymer, PMG-Te. The $M_{\mathrm{w}}$ and PDI of PMG-Te were $28000 \mathrm{~g} / \mathrm{mol}$ and 1.18 , respectively (Fig. 1), indicating that the PMG-Te synthesized by this method possessed a narrow molecular weight distribution. PMG-Te dissolved in dimethylformamide (DMF) and dimethylsulfoxide (DMSO), but not in alcohol. Although samples of PMG-Te possessing a larger molar ratio (more than $15 \mathrm{~mol} \%$ ) of Te to MGP were synthesized, these block copolymers did not dis- 
solve in DMF, DMSO or other solvents. Therefore, PMG-Te containing $15 \mathrm{~mol} \%$ of Te was used in the following experiments. Direct dissolution of amphiphilic block copolymer is in most cases impossible, so that dialysis method is used to form polymeric micelles. ${ }^{28)}$ As direct dissolution of PMG-Te into water was also impossible, polymeric micelles of PMGTe were prepared by dialysis method (see Experimental).

Light Scattering The change in light scattering intensity of the PMG-Te solution upon dialysis was measured. A considerable increase in light scattering intensity was observed after dialysis of the block copolymer solution, although the solution was visibly transparent. This result suggested that polymeric micelles were formed from this copolymer. Depending on the composition of the block copolymers, two types of micelles can be distinguished: star and crew-cut. The star micelle is usually made from block copolymers in which the corona-forming blocks are much longer than the core-forming blocks, while the crew-cut micelle is made from copolymers in which the core-forming blocks are much longer. It is known that a multitude of different micellar shapes (spheres, cylinders, vesicles, compound vesicles) exists for crew-cut micelles. ${ }^{29-34)}$ When a unitary solvent, such as water, is used as a selective solvent to form star micelles, spherical micelles are obtained and other micellar shapes not formed within our knowledge. ${ }^{1-10,31,32,35-38)}$ The PMG-Te possessed much longer hydrophilic blocks than hydrophobic blocks. Therefore, a spherical micelle would be formed by the aggregation of PMG-Te.

The diameter distribution of PMG-Te was measured by dynamic light scattering (DLS) in water, and the results are shown in Fig. 2 and Table 1. PMG-Te showed a unimodal size distribution (Fig. 2A), and its mean diameter (number average) was found to be $41.9 \mathrm{~nm}$. As the molecular weight of amphiphilic block copolymer used was $28000 \mathrm{~g} / \mathrm{mol}$, the mean diameter of unimer might be $1-2 \mathrm{~nm}$. The mean diameter of PMG-Te was much larger than that expected for unimer, so that it was suggested that many molecules aggregated to form micelles. Similar results were obtained for other polymeric micelles. ${ }^{2-6,39)}$ Addition of $0.05(\mathrm{w} / \mathrm{v}) \%$ sodium dodecyl sulfate (SDS) as surfactant brought about a drastic shift of the peak to a smaller size (Fig. 2B), indicating the disruption of polymeric micelles. Yokoyama et al. also reported that the polymeric micelle fabricated from adriamycin-conjugated poly(ethylene glycol)-poly(aspartic acid) block copolymer was disrupted by the addition of SDS. ${ }^{39}$ ) This phenomena may be explained by the interaction of block copolymer and SDS. Thus, the hydrophobic interaction between block copolymers may be interrupted by SDS. As shown in Table 1, the mean diameter of PMG-Te with $0.05(\mathrm{w} / \mathrm{v}) \%$ SDS was found to be slightly larger than that with $0.1(\mathrm{w} / \mathrm{v}) \%$ SDS, suggesting that the degree of disruption of the micellar structure was dependent on the concentration of the surfactant.

To obtain information on micellar shape, the angular dependence of light scattering from the micelle solution was estimated from the DLS measurements. Figure 3 shows the dependence of the scaled characteristic line width $\left(\Gamma / K^{2}\right)$ on the scattering vector $\left(K^{2}\right)$, corresponding to the scattering angle. It is known that spherical micelles show no angle dependence of the scaled characteristic line width on the scattering vector. ${ }^{40)}$ As shown in Fig. 3 , the value of $\Gamma / K^{2}$ was al-
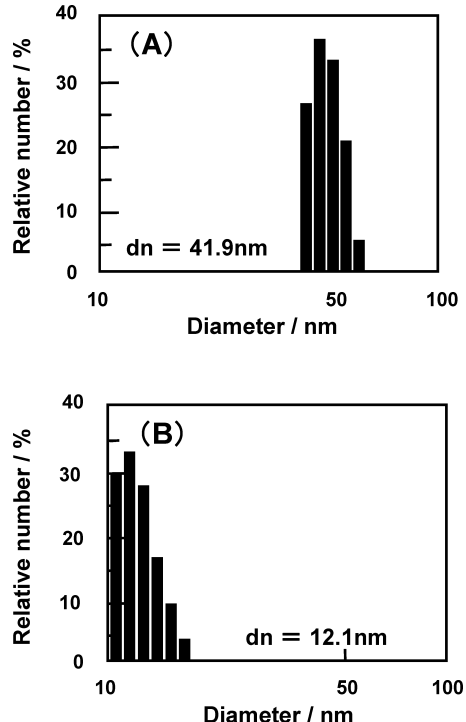

Fig. 2. Diameter Distribution of PMG-Te Micelle in Water without SDS (A) and with $0.05(\mathrm{w} / \mathrm{v}) \%$ SDS (B)

$\mathrm{dn}$ : number average diameter.

Table 1. Mean Diameter of PMG-Te Micelles Measured by Dynamic Light Scattering

\begin{tabular}{ccc}
\hline \hline $\begin{array}{c}\text { SDS } \\
\text { concentration } \\
(\mathrm{w} / \mathrm{v}) \%\end{array}$ & $\begin{array}{c}\text { Number average } \\
\text { diameter } \\
(\mathrm{nm})\end{array}$ & $\begin{array}{c}\text { Weight average } \\
\text { diameter } \\
(\mathrm{nm})\end{array}$ \\
\hline 0 & $41.9 \pm 9.4$ & $42.6 \pm 3.5$ \\
0.05 & $12.1 \pm 9.2$ & $13.1 \pm 3.1$ \\
0.10 & $1.2 \pm 0.0$ & $1.3 \pm 0.0$ \\
\hline
\end{tabular}

Number and weight average diameter are shown as the mean \pm S.D.

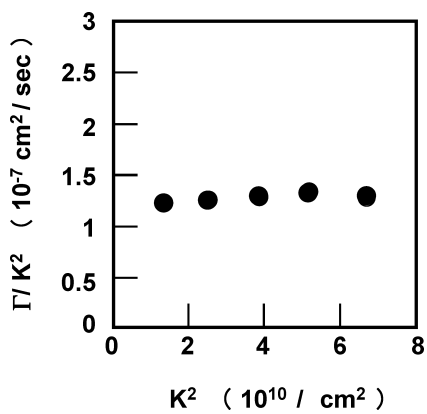

Fig. 3. Plots of the Scaled Average Characteristic Line Width $\left(\Gamma / K^{2}\right)$ against the Magnitude of the Scattering Vector $\left(K^{2}\right)$ of PMG-Te Micelles

most constant against $K^{2}$, indicating that the polymeric micelles were spherical, as expected.

\section{Conclusions}

The findings of the present study can be summarized as follows: We have presented the first example of the formation of polymeric micelles from an amphiphilic block copolymer synthesized by mechanochemical solid-state polymerization. An amphiphilic block copolymer possessing a narrow molecular weight distribution was synthesized by this method from the homopolymer of 6-O-methacryloyl-Dgalactose, PMG, and 7-(2-methacryloyloxy)ethylcarbamoyl)theophylline, Te. Polymeric micelles were readily prepared 
from this amphiphilic block copolymer by a dialysis method. The mean diameter of the micelles measured by dynamic light scattering was about $40 \mathrm{~nm}$. A narrow diameter distribution was observed in the polymeric micelles obtained. Addition of SDS to the polymeric micelle solution caused a drastic shift to a smaller micelle size, suggesting that these micelles were disrupted by the addition of SDS.

These results suggested that block copolymers synthesized by mechanochemical solid-state polymerization could be better for the preparation of polymeric micelles than those obtained by living polymerization. Mechanochemical solidstate polymerization can proceed at room temperature and is applicable to a variety of vinyl monomers possessing functional groups such as drugs. Therefore, this method could be more convenient than living polymerization for the synthesis of amphiphilic block copolymers utilized in the preparation of polymeric micelles. The nature of drug release from polymeric micelles prepared by this method will be the subject of a forthcoming paper.

\section{References}

1) Yokoyama M., Miyauchi M., Yamada N., Okano T., Kataoka K., Inoue S., J. Control. Rel., 11, 269-278 (1990).

2) Kohori F., Sakai K., Aoyagi T., Yokoyama M., Sakurai Y., Okano T., J. Control. Rel., 55, 87—98 (1998).

3) Yasugi K., Nagasaki Y., Kato M., Kataoka K., J. Control. Rel., 62, 89-100 (1999).

4) Akiyoshi K., Kang E.-C., Kurumada S., Sunamoto J., Principi T., Winnik F. M., Macromolecules, 33, 3244-3249 (2000).

5) Katayama Y., Sonoda T., Maeda M., Macromolecules, 34, 8569—8573 (2001).

6) Kataoka K., Harada A., Nagasaki Y., Adv. Drug Deliv. Rev., 47, 113131 (2001) and references cited therein.

7) Savic R., Luo L., Eisenberg A., Maysinger D., Science, 300, 615-618 (2003).

8) Francis M. F., Cristea M., Winnik F. M., Pure Appl. Chem., 76, 13211335 (2004) and references cited therein.

9) Bae Y., Nishiyama N., Fukushima S., Koyama H., Yasuhiro M, Kataoka K., Bioconjugate Chem., 16, 122-130 (2005).

10) Djordjevic J., Barch M., Uhrich K. E., Pharm. Res., 22, 24-32 (2005).

11) Miyamoto M., Sawamoto M., Higashimura T., Macromolecules, 17, $265-268$ (1984).
12) Faust R., Kennedy J. P., Polym. Bull., 15, 317-323 (1986).

13) Faust R., Kennedy J. P., J. Polym. Sci., Polym. Chem. Ed., A25, $1847-$ 1869 (1987).

14) Szwarc M., Nature (London), 178, 1168-1169 (1956).

15) Szwarc M., Levy M., Milkovich R., J. Am. Chem. Soc., 78, 26562657 (1956).

16) Kuzuya M., Kondo S., Noguchi A., Macromolecules, 24, 4047-4053 (1991).

17) Kuzuya M., Kondo S., Chem. Pharm. Bull., 39, 3018-3022 (1991).

18) Kuzuya M., Kondo S., Murase K., J. Phys. Chem., 97, 7800-7802 (1993).

19) Kondo S., Murase K., Kuzuya M., Chem. Pharm. Bull., 42, 768-773 (1994).

20) Kondo S., Hosaka S., Kuzuya M., Chem. Pharm. Bull., 46, 669-673 (1998).

21) Kondo S., Kuzuya M., Curr. Trends Polym. Sci., 3, 1-23 (1998).

22) Kondo S., Hosaka S., Hatakeyama I., Kuzuya M., Chem. Pharm. Bull., 46, 1918-1923 (1998).

23) Kondo S., Hatakeyama I., Hosaka S., Kuzuya M., Chem. Pharm. Bull., 48, 1882-1885 (2000).

24) Kondo S., Yakugaku Zasshi, 120, 1337-1346 (2000).

25) Kondo S., Sasai Y., Kuzuya M., Furukawa S., Chem. Pharm. Bull., 50, 1434-1438 (2002).

26) Kondo S., Sasai Y., Hosaka S., Ishikawa T., Kuzuya M., J. Polym. Sci. Part A: Polym. Chem., 42, 4161-4167 (2004).

27) Kondo S., Shichijyou D., Sasai Y., Yamauchi Y., Kuzuya M., Chem. Pharm. Bull., 53, 863-865 (2005).

28) Förster S., Hermsdorf N., Leube W., Schnablegger H., Regenbrecht M., Akari S., Lindner P., Böttcher C., J. Phys. Chem. B, 103, 66576668 (1999).

29) Gao Z., Varshney S. K., Wong S., Eisenberg A., Macromolecules, 27, 7923-7927 (1994).

30) Zhang L., Barlow R. J., Eisenberg A., Macromolecules, 28, 60556066 (1995).

31) Zhang L., Eisenberg A., Science, 268, 1728-1731 (1995).

32) Yu K., Zhang L., Eisenberg A., Langmuir, 12, 5980-5984 (1996).

33) Zhang L., Yu K., Eisenberg A., Science, 272, 1777-1779 (1996).

34) Yu K., Zhang L., Eisenberg A., Langmuir, 13, 2578-2581 (1997).

35) Yu K., Eisenberg A., Macromolecules, 29, 6359—6361 (1996).

36) Ding J., Liu G., Macromolecules, 30, 655-657 (1997).

37) Zhang L., Eisenberg A., Macromolecules, 32, 2239-2249 (1999).

38) Liang Y., Li Z., Li F., New J. Chem., 24, 323-328 (2000).

39) Yokoyama M., Miyauchi M., Yamada N., Okano T., Sakurai Y., Kataoka K., Inoue S., Cancer Res., 50, 1693-1700 (1990).

40) Iijima M., Nagasaki Y., Okada T., Kato M., Kataoka K., Macromolecules, 32, 1140-1146 (1999). 